\title{
Cutting Efficiency of Instruments with Different Movements: a Comparative Study
}

\section{Luigi Tocci $^{1}$, Gianluca Plotino ${ }^{1}$, Dina Al-Sudani ${ }^{2}$, Alessio Giansiracusa Rubini ${ }^{1}$, Gianpaolo Sannino ${ }^{3}$, Lucila Piasecki $^{4}$, Ermanno Putortì ${ }^{1}$, Luca Testarelli ${ }^{1}$, Gianluca Gambarini ${ }^{1}$}

\author{
${ }^{1}$ Department of Endodontics, "Sapienza" University of Rome, Italy. \\ ${ }^{2}$ Department of Restorative Dental Science, College of Dentistry, King Saud University, Riyadh, Saudi Arabia. \\ ${ }^{3}$ University of Tor Vergata, Rome, Italy. \\ ${ }^{4}$ Universidade Paranaense UNIPAR Cascavel, Brasil.
}

\author{
Corresponding Author: \\ Luigi Tocci \\ Via San Francesco, 49-04010 Sonnino (LT) \\ Italy \\ E-mail: 1uigi.tocci@libero.it
}

\section{ABSTRACT}

Objectives: The aim of the present study was to evaluate the cutting efficiency of two new reciprocating instruments, Twisted File Adaptive and WaveOne Primary.

Material and Methods: 10 new Twisted File Adaptive (TF Adaptive) (SybronEndo, Glendora, CA, USA) and 10 new WaveOne Primary files (Dentsply Maillefer, Ballaigues, Switzerland) were activated using a torque-controlled motor, respectively TFA motor (SybronEndo, Glendora, CA, USA) and Silver motor (VDW, Munich, Germany). The device used for the cutting test consisted on a mainframe to which a mobile plastic support for the hand-piece is connected and a stainless-steel block containing a Plexiglas block against which the cutting efficiency of the instruments was tested. The length of the block cut in 1 minute was measured in a computerized program with a precision of $0.1 \mathrm{~mm}$. Mean and standard deviations of each group were calculated and data were statistically analyzed with one-way ANOVA and Bonferroni $t$ test $(\mathrm{P}<0.05)$.

Results: TF Adaptive displayed significantly greater maximum penetration depth than WaveOne Primary $(\mathrm{P}<0.05)$. In fact, TF Adaptive instruments (Group 1) cut the Plexiglas block to a mean depth of 8.7 (SD 0.5) mm, while WaveOne Primary instruments cut the Plexiglas block to a mean depth of 6.4 (SD 0.3) mm.

Conclusions: Twisted File Adaptive instruments demonstrated statistically higher cutting efficiency than WaveOne instruments.

Keywords: endodontics; instrumentation; materials testing.

\section{Accepted for publication: 9 February 2015}

To cite this article:

Tocci L, Plotino G, Al-Sudani D, Rubini AG, Sannino G, Piasecki L, Putortì E, Testarelli L, Gambarini G. Cutting Efficiency of Instruments with Different Movements: a Comparative Study.

J Oral Maxillofac Res 2015;6(1):e6

URL: http://www.ejomr.org/JOMR/archives/2015/1/e6/v6n1e6.pdf

doi: $10.5037 /$ jomr.2015.6106 


\section{INTRODUCTION}

The cutting efficiency is an important property of nickel-titanium (NiTi) endodontic instruments [1]. With the advancement in technology, NiTi endodontic instruments nowadays come in a variety of designs and manufacturing processes, each aiming at improving performance and safety [2-4]. The capability of an instruments to efficiently remove dentin is a complex interrelationship of different parameters, including number and depth of flutes, helical and rake angle, cross-sectional area and design, sterilization, tip design, chip removal capacity, alloy hardness and manufacturing processes including electropolishing, heat treatments, coating of the instruments []․ Cutting efficiency is also dependent on instrument motion [6]. Recently, reciprocating NiTi instruments have been introduced to the market [7-9]. Gambarini et al. [10] showed that changing the motion by modifying the angles of reciprocation could significantly affect the resistance to fracture of the instruments, and also the ability to cut dentin and remove debris. These findings were confirmed in a recent study from Plotino et al [1], comparing cutting ability of two reciprocating instruments: WaveOne and Reciproc instruments.

More recently, a new innovative reciprocating motion and instrumentation technique (TF Adaptive) (SybronEndo, Glendora, CA, USA) was introduced [11]. It has been developed to combine the advantages of both continuous rotation and reciprocation. More precisely, when the TF Adaptive instrument is not (or very lightly) stressed, the movement can be described as an interrupted continuous rotation. On the contrary, while negotiating the canal, owing to increased instrumentation stress, the motion of the TF Adaptive instrument changes into reciprocation with specifically designed clockwise $(\mathrm{CW})$ and counterclockwise $(\mathrm{CCW})$ angles. Moreover, these angles are not constant, but vary depending on the anatomical complexities and the intra-canal stress.

Although extensive studies were conducted on the cutting ability of hand and rotary endodontic instruments [12-20], little data are available on the cutting efficiency of these new reciprocating instruments $[1,6]$. Moreover, no scientific article was published to evaluate whether differences in motion may affect or not cutting ability. Thus, the aim of the present study was to compare the cutting efficiency of TF Adaptive and WaveOne Primary instruments.

\section{MATERIAL AND METHODS}

A total of 20 new NiTi reciprocating instruments $25 \mathrm{~mm}$ in length were used in the present study: 10 TF Adaptive (tip size 25, .08 taper; SybronEndo, Glendora, CA, USA) and 10 WaveOne Primary files (tip size 25, .08 variable taper; DentsplyMaillefer, Ballaigues, Switzerland). All of the instruments had been previously inspected using an optical stereomicroscope at x20 magnification for morphological analysis and for any signs of visible deformation. If defective instruments were found, they were discarded. Group 1 instruments (TF Adaptive, $\mathrm{n}=10$ ) were activated with the "TFAdaptive" program using a 8:1 reduction hand-piece powered by the torque-controlled motor Elements Motor (SybronEndo, Glendora, CA, USA), whilst Group 2 instruments (WaveOne Primary, $n=10$ ) were activated with the program "WaveOne ALL" using a 6:1 reduction hand-piece (Sirona Dental ystems $\mathrm{GmbH}$, Bensheim, Germany) powered by a torquecontrolled motor (Silver, VDW, Munich, Germany). Special Plexiglas plates $(30 \times 30 \times 1 \mathrm{~mm}$; Inplex, Rome, Italy), created from the same original raw material, were used to eliminate variability due to possible different mechanical characteristics of dentine specimens. Each instrument was used only once, while each plastic block was used to test one instrument from each of the two groups tested, thus 10 blocks were used. Cutting efficiency of all instruments was determined by means of a specially designed testing device already used in previous studies $[\underline{1}, \underline{6}]$. The device consists of a mainframe to which a mobile plastic support is connected for the electric hand-piece and a stainless-steel block containing the artificial canals. The electric hand-piece was mounted upon a mobile device connected to a fixed weight that for gravity drove the horizontal instrument against the Plexiglas block in a precise and reproducible way. The same 150 grams weight was used to test all instruments, as a pilot study indicated this was the ideal weight to prevent bending of the instrument selected and to guarantee a certain length of cutting depth in the unit of time selected for this study. A notch of $1 \mathrm{~mm}$ in depth and width was created on the lateral wall of the Plexiglas plate that measured $1 \mathrm{~mm}$ in thickness to prevent the instruments from slipping out the smooth surface of the plastic. The plastic support for the hand-piece allowed for precise and simple three-dimensional alignment and positioning of the instrument, as soon as it came perpendicularly into contact with the notch created on the wall of the Plexiglas specimen without bending. 
The cutting efficiency was tested $14 \mathrm{~mm}$ from the tip of each instrument to avoid their deflection when the weight was applied nearer to the tip, as reported in a pilot study. Once everything was fixed, the motor of the testing device was switched on and the instrument removed material and penetrated actively. An air compressor was attached and used during all the experiment to permit removal of plastic debris created by the instrument during the test. Each instrument was tested in linear cutting unidirectional lateral motion and the maximum penetration depth of the instruments was the criterion for cutting efficiency and the basis for the comparison as a function of time. The precise length of the plastic block cut in 1 minute was measured in $\mathrm{mm}$ using a computerized program (Adobe Photoshop CS4) with a precision of $0.1 \mathrm{~mm}$. The $1 \mathrm{~mm}$ notch was subtracted to the length obtained.

\section{Statistical analysis}

The results were expressed as means and standard deviations (M [SD]) for each group and data were statistically analysed for significant differences between group means with the one-way ANOVA and Bonferroni t-test, with the level of significance set at $\mathrm{P}<0.05$.

\section{RESULTS}

TF Adaptive displayed significantly greater maximum penetration depth than WaveOne Primary $(\mathrm{P}<0.05)$. In fact, TF Adaptive instruments (Group 1) cut the Plexiglas block to a mean depth of $8.7(0.5) \mathrm{mm}$, while WaveOne Primary instruments cut the Plexiglas block to a mean depth of $6.4(0.3) \mathrm{mm}$.

\section{DISCUSSION}

Many authors have evaluated cutting ability of endodontic instruments as a result of debris generated during the preparation of extracted teeth, from weight loss of tooth samples and resin blocks after instrumentation, as changes in the dentin thickness removed or in root canal volume, from direct evaluation by clinician during preparation, measuring the mass lost from a Plexiglas plate by the instrument in cutting or the maximum penetration depth of the instrument into the lumen of special plastic samples with a cylindrical canal and in terms of preparation time [12-20].
In this study, a new device has been used to test cutting ability of TF Adaptive and WaveOne Primary instruments. This device is specifically developed for cutting test, with a methodology validated in previous published researches $[\underline{1}, \underline{6}]$. Cutting efficiency was examined by operating the instruments on plastic samples, because different studies discouraged testing with teeth for their variable hardness and water content $[\underline{16}, \underline{21}, 22]$. The use of Plexiglas plates has guaranteed standardized experimental conditions, allowing direct comparisons of the cutting ability of different instruments tested on identical samples [17] and eliminating variations in hardness that may influence results; however, plastic does not exhibit the same properties as dentin and thus may not provide clinically relevant data. The testing device generates a motion that not reproduce the action of instrumenting a root canal and, consequently, further studies are required to correlate cutting efficiency with the quality of root canal preparation [23-25].

The results of this study showed statistically significant differences between the cutting ability of TF Adaptive and WaveOne Primary instruments. In fact, TF Adaptive demonstrated a greater cutting efficiency than WaveOne Primary file, which could be explained by their adaptive motion. TF Adaptive employs a patented unique motion technology, which automatically adapts to instrumentation stress. When the TF Adaptive instrument is not (or very lightly) stressed in the canal, the movement can be described as an interrupted continuous rotation, allowing better cutting efficiency, since cross-sectional and flute design are meant to perform at their best in a CW motion. On the contrary, while negotiating the canal, due to increased instrumentation stress, the motion of the TF Adaptive instrument changes into a reciprocation mode, with specifically designed $\mathrm{CW}$ and $\mathrm{CCW}$ angles (not constant). This adaptive motion is therefore meant to reduce the risk intracanal failure, due to the fact that the best movement for each different clinical situation is automatically selected by the Adaptive motor; angles of reciprocation influenced cyclic fatigue resistance of WaveOne instruments instead [26]. Cutting efficiency and cleaning effectiveness of mechanical NiTi instruments are closely related [27]. The removal of cut dentin chips is important to reduce clogging of the cutting blades and so, as some studies demonstrated, the debris removal capability determines the efficiency of mechanical instruments [27,28]. WaveOne might not provide enough space for debris to be displaced, thus reducing their cutting ability compared to TF Adaptive. 
Further studies are needed to better understand the cutting properties of mechanical endodontic instruments. Cutting efficiency should be tested on dentine blocks and related to more clinical situations to evaluate for example the possible influence of root canal irrigants or debris removal capability on the cutting efficiency of NiTi files and the effect of cutting efficiency on root canal transportation. Furthermore, it may be interesting to also evaluate the cutting efficiency at different instruments' level (coronal, middle and apical part).

\section{CONCLUSIONS}

The results of the present study reported that TF Adaptive instruments demonstrated statistically higher cutting efficiency than WaveOne, when tested at 14 mm length from the tip.

\section{ACKNOWLEDGMENTS AND DISCLOSURE STATEMENTS}

The authors report no conflicts of interest related to this study.

\section{REFERENCES}

1. Plotino G, Giansiracusa Rubini A, Grande NM, Testarelli L, Gambarini G. Cutting efficiency of Reciproc and WaveOne reciprocating instruments. J Endod. 2014 Aug;40(8):1228-30. [Medline: 25069938] [doi: 10.1016/j.joen.2014.01.041]

2. Plotino G, Grande NM, Cordaro M, Testarelli L, Gambarini G. A review on cyclic fatigue testing of nickel-titanium rotary instruments. J Endod. 2009 Nov;35(11):1469-76. [Medline: 25069938] [doi: 10.1016/j.joen.2009.06.015]

3. Plotino G, Grande NM, Cotti E, Testarelli L, Gambarini G. Blue treatment enhances cyclic fatigue resistance of Vortex nickel-titanium rotary files. J Endod. 2014 Sep;40(9):1451-3. [Medline: 25146031] [doi: 10.1016/j.joen.2014.02.020]

4. Plotino G, Testarelli L, Al-Sudani D, Pongione G, Grande NM, Gambarini G. Fatigue resistance of rotary instruments manufactured using different nickel-titanium alloys: a comparative study. Odontology. 2014 Jan;102(1):31-5. [Medline: 23076495] [doi: 10.1007/s10266-012-0088-8]

5. Peters OA. Current challenges and concepts in the preparation of root canal systems: a review. J Endod. 2004 Aug;30(8):559-67. [Medline: 15273636] [doi: 10.1097/01.DON.0000129039.59003.9D]

6. Giansiracusa Rubini A, Plotino G, Al-Sudani D, Grande NM, Putortì E, Sannino G, Cotti E, Testarelli L, Gambarini G. A new device to test cutting efficiency of endodontic mechanical instruments. Med Sci Monit. 2014 Mar 6;20:374-8. [Medline: 24603777] [doi: 10.12659/MSM.890119] [doi: 10.12659/MSM.890119]

7. Plotino G, Grande NM, Testarelli L, Gambarini G. Cyclic fatigue of Reciproc and WaveOne reciprocating instruments. Int Endod J. 2012 Jul;45(7):614-8. [Medline: 22268461] [doi: 10.1111/j.1365-2591.2012.02015.x]

8. Pedullà E, Grande NM, Plotino G, Gambarini G, Rapisarda E. Influence of continuous or reciprocating motion on cyclic fatigue resistance of 4 different nickel-titanium rotary instruments. J Endod. 2013 Feb;39(2):258-61. [Medline: 23321241] [doi: 10.1016/j.joen.2012.10.025]

9. Pedullà E, Grande NM, Plotino G, Palermo F, Gambarini G, Rapisarda E. Cyclic fatigue resistance of two reciprocating nickel-titanium instruments after immersion in sodium hypochlorite. Int Endod J. 2013 Feb;46(2):155-9. [Medline: 22831397] [doi: 10.1111/j.1365-2591.2012.02100.x]

10. Gambarini G, Rubini AG, Al-Sudani D, Gergi R, Culla A, De Angelis F, Di Carlo S, Pompa G, Osta N, Testarelli L. Influence of different angles of reciprocation on the cyclic fatigue of nickel-titanium endodontic instruments. J Endod. 2012 Oct;38(10):1408-11. [Medline: 22980189] [doi: 10.1016/j.joen.2012.05.019]

11. Gambarini G, Gergi R, Naaman A, Osta N, Al-Sudani D. Cyclic fatigue analysis of twisted file rotary $\mathrm{NiTi}$ instruments used in reciprocating motion. Int Endod J. 2012 Sep;45(9):802-6. [Medline: 22429241] [doi: 10.1111/j.1365-2591.2012.02036.x]

12. Fayyad DM, Elhakim Elgendy AA. Cutting efficiency of twisted versus machined nickel-titanium endodontic files. J Endod. 2011 Aug;37(8):1143-6. [Medline: 21763910] [doi: 10.1016/j.joen.2011.03.036]

13. Vinothkumar TS, Miglani R, Lakshminarayananan L. Influence of deep dry cryogenic treatment on cutting efficiency and wear resistance of nickel-titanium rotary endodontic instruments. J Endod. 2007 Nov;33(11):1355-8. [Medline: 17963963] [doi: 10.1016/j.joen.2007.07.017]

14. Rapisarda E, Bonaccorso A, Tripi TR, Fragalk I, Condorelli GG. The effect of surface treatments of nickel-titanium files on wear and cutting efficiency. Oral Surg Oral Med Oral Pathol Oral Radiol Endod. 2000 Mar;89(3):363-8. [Medline: 10710464 ]

15. Wan J, Rasimick BJ, Musikant BL, Deutsch AS. Cutting efficiency of 3 different instrument designs used in reciprocation. Oral Surg Oral Med Oral Pathol Oral Radiol Endod 2010 May;109(5):e82-5. [Medline: 20416525] [doi: 10.1016/j.tripleo.2009.12.037]

16. Haikel Y, Serfaty R, Lwin TT, Allemann C. Measurement of the cutting efficiency of endodontic instruments: a new concept. J Endod. 1996 Dec;22(12):651-6. [Medline: 9220749] 
17. Schäfer E, Oitzinger M. Cutting efficiency of five different types of rotary nickel-titanium instruments. J Endod. 2008 Feb;34(2):198-200. [Medline: 18215681] [doi: 10.1016/j.joen.2007.10.009]

18. Schäfer E, Erler M, Dammaschke T. Comparative study on the shaping ability and cleaning efficiency of rotary Mtwo instruments. Part 1. Shaping ability in simulated curved canals. Int Endod J. 2006 Mar;39(3):196-202. [Medline: 16507073]

19. Burklein S, Benten S, Schäfer E. Shaping ability of different single-file systems in severely curved root canals of extracted teeth. Int Endod J. 2013 Jun;46(6):590-7. [Medline: 23240965] [doi: 10.1111/iej.12037]

20. Kim JW, Griggs JA, Regan JD, Ellis RA, Cai Z. Effect of cryogenic treatment on nickel-titanium endodontic instruments. Int Endod J. 2005 Jun;38(6):364-71. [Medline: 15910471]

21. Shen Y, Haapasalo M. Three-dimensional analysis of cutting behavior of nickel-titanium rotary instruments by microcomputed tomography. J Endod. 2008 May;34(5):606-10. [Medline: 18436045] [doi: 10.1016/j.joen.2008.02.025]

22. Machian GR, Peters DD, Lorton L. The comparative efficiency of four types of endodontic instruments. J Endod. 1982 Sep;8(9):392-402. [Medline: 6957534$]$

23. Berutti E, Paolino DS, Chiandussi G, Alovisi M, Cantatore G, Castellucci A, Pasqualini D. Root Canal Anatomy Preservation of WaveOne Reciprocating Files with or without Glide Path. J Endod. 2012 Jan;38(1):101-4. [Medline: 22152630] [doi: 10.1016/i.joen.2011.09.030]

24. Marzouk AM, Ghoneim AG. Computed tomographic evaluation of canal shape instrumented by different kinematics rotary nickel-titanium systems. J Endod. 2013 Jul;39(7):906-9. [Medline: 23791261] [doi: 10.1016/j.joen.2013.04.023]

25. Versiani MA, Leoni GB, Steier L, De-Deus G, Tassani S, Pecora JD, de Sousa-Neto MD. Micro-computed tomography study of oval-shaped canals prepared with the Self-adjusting File, Reciproc, WaveOne, and ProTaper Universal systems. J Endod. 2013 Aug;39(8):1060-6. [Medline: 23880278] [doi: 10.1016/j.joen.2013.04.009]

26. Saber Sel D, Abu El Sadat SM. Effect of altering the reciprocation range on the fatigue life and the shaping ability of WaveOne nickel-titanium instruments. J Endod. 2013 May;39(5):685-8. [Medline: 23611391] [doi: 10.1016/j.joen.2012.12.007]

27. Bergmans L, van Cleynenbreugel J, Wevers M, Lambrechts P. Mechanical root canal preparation with NiTi rotary instruments: rationale, performance and safety. Status report for the American Journal of Dentistry. Am J Dent. 2001 Oct;14(5):324-33. [Medline: 11803999]

28. Schäfer E. Relationship between design features of endodontic instruments and their properties. Part 1. Cutting efficiency. J Endod. 1999 Jan;25(1):52-5. [doi: 10.1016/S0099-2399(99)80400-2]

\section{To cite this article:}

Tocci L, Plotino G, Al-Sudani D, Rubini AG, Sannino G, Piasecki L, Putortì E, Testarelli L, Gambarini G. Cutting Efficiency of Instruments with Different Movements: a Comparative Study.

J Oral Maxillofac Res 2015;6(1):e6

URL: http://www.ejomr.org/JOMR/archives/2015/1/e6/v6n1e6.pdf

doi: $10.5037 /$ jomr.2015.6106

Copyright (C) Tocci L, Plotino G, Al-Sudani D, Rubini AG, Sannino G, Testarelli L, Gambarini G. Published in the JOURNAL OF ORAL \& MAXILLOFACIAL RESEARCH (http://www.ejomr.org), 31 March 2015.

This is an open-access article, first published in the JOURNAL OF ORAL \& MAXILLOFACIAL RESEARCH, distributed under the terms of the Creative Commons Attribution-Noncommercial-No Derivative Works 3.0 Unported License, which permits unrestricted non-commercial use, distribution, and reproduction in any medium, provided the original work and is properly cited. The copyright, license information and link to the original publication on (http://www.ejomr.org) must be included. 